OPEN ACCESS

Edited by:

Kevin Couper,

University of Manchester,

United Kingdom

Reviewed by:

Noah Butler

The University of lowa, United States Jason Scott Stumhofer,

University of Arkansas for Medical

Sciences, United States

James M. Brewer,

University of Glasgow,

United Kingdom

${ }^{*}$ Correspondence:

Michelle Wykes

Michelle.Wykes@qimrberghofer.edu.au

Specialty section:

This article was submitted to Microbial Immunology, a section of the journal

Frontiers in Immunology

Received: 02 October 2018 Accepted: 29 November 2018 Published: 14 December 2018

Citation:

Faleiro R, Karunarathne DS, Horne-Debets $J M$ and Wykes $M$ (2018) The Contribution of

Co-signaling Pathways to Anti-malarial

$T$ Cell Immunity.

Front. Immunol. 9:2926.

doi: 10.3389/fimmu.2018.02926

\section{The Contribution of Co-signaling Pathways to Anti-malarial T Cell Immunity}

\author{
Rebecca Faleiro, Deshapriya S. Karunarathne, Joshua M. Horne-Debets and \\ Michelle Wykes*
}

QIMR Berghofer Medical Research Institute, Brisbane, QLD, Australia

Plasmodium spp., the causative agent of malaria, caused 212 million infections in 2016 with 445,000 deaths, mostly in children. Adults acquire enough immunity to prevent clinical symptoms but never develop sterile immunity. The only vaccine for malaria, RTS,S, shows promising protection of a limited duration against clinical malaria in infants but no significant protection against severe disease. There is now abundant evidence that $T$ cell functions are inhibited during malaria, which may explain why vaccine are not efficacious. Studies have now clearly shown that $T$ cell immunity against malaria is subdued by multiple the immune regulatory receptors, in particular, by programmed cell-death-1 (PD-1). Given there is an urgent need for an efficacious malarial treatment, compounded with growing drug resistance, a better understanding of malarial immunity is essential. This review will examine molecular signals that affect $T$ cell-mediated immunity against malaria.

Keywords: malaria, immunity, inhibitory receptors on T cells, stimulatory receptors on T cells, Immuno-therapy, chronic malaria, cerebral malaria, experimental cerebral malaria

\section{INTRODUCTION}

Malaria is a disease caused by parasites of the Plasmodium spp. of which there are six species that infect humans: $P$. falciparum, $P$. vivax, $P$. ovale, $P$. malariae, $P$. knowlesi, and $P$. cynomolgi. Malaria causes serious morbidity in large populations (1) but unlike many other infections, infected individuals do not become resistant to subsequent infections. While adults will develop protection from severe symptoms, chronic, and low grade infections remain a major threat to eradication efforts due to a vast number of carriers. Overall, while tremendous progress has been made in controlling malaria, no vaccine has been completely successful and as such new approaches are required.

Malaria parasites, introduced by mosquitos, first infect the liver and then blood. It is the bloodstage infection that causes the symptoms and lethality associated with malaria. Infants and children in endemic areas are highly susceptible to malaria during the first 5 years but slowly gain resistance to severe, life-threatening infections and then to clinical disease (1). However, sterile immunity is rarely attained (2). As such, there have been well over 100 clinical trials to develop a malaria vaccine and the only one to be approved for use is a pre-erythrocytic vaccine, RTS,S, which comprises of an immunogenic fragment of the circumsporozoite protein of $P$. falciparum with the hepatitis B surface antigen. In field trials, the vaccine showed $30-50 \%$ efficacy in the first year following vaccination and this dropped to only $16 \%$ in the fourth year, indicating that protective immunity is at some point compromised. 
Optimal immune responses against infections require a balance between pro-inflammatory and regulatory immune responses. Pro-inflammatory responses drive protective immunity while regulatory responses control these immune response to prevent tissue damage and also prevent autoimmunity. Immunity against malaria requires a combination of antibodies and $\mathrm{T}$ cell responses. Recent research indicates that $\mathrm{CD} 4^{+} \mathrm{T}$ cells, which consist of several helper-subtypes that shape immune responses, play a much larger role in diminished malarial immunity than previously understood.

Original studies which transferred serum from malariaprotected adults to children, established that antibodies had a critical role in the clearance of parasites (3). However, mouse models have underpinned our understanding of T cell-immunity against malaria. Studies with $P$. chabaudi, which causes a rapidly resolving acute parasitemia followed by multiple recrudescent bouts over many months showed that $\mathrm{CD} 4^{+} \mathrm{T}$ cells are required to control malaria by their ability to help B cells $(4,5)$. The resultant antibodies promote parasite clearance by phagocytosis (6). Other studies with P. chabaudi showed that $\mathrm{CD} 4^{+} \mathrm{T}$ cells control the peak of parasitemia in the primary phase of acute blood stage infections $(7,8)$ via production of high levels of interferon- $\gamma($ IFN- $\gamma)$ and tumor necrosis factor alpha (TNF- $\alpha$ ) (9-11). Studies have also shown that IFN- $\gamma$ and TNF- $\alpha$ cooperate to induce nitric oxide synthase expression in the spleen to control peak parasite burden (12). In contrast, P. yoelii YM, P. yoelii $\mathrm{XL}$ and $P$. berghei ANKA are severe, lethal infections with the last causing cerebral malaria $(\mathrm{CM})$ as this parasite sequesters from the blood into deep tissues including the brain. Studies in mice revealed that $\mathrm{CD} 8^{+} \mathrm{T}$ cells sequester in the brain during cerebral malaria (13) and with early production of IFN- $\gamma$ (14) were responsible for mortality. Similarly, $\mathrm{CD}^{+} \mathrm{T}$ cells mediate the loss of marginal metallophilic macrophages and damage to splenic architecture (15). However, several studies have now shown a role for these cells in controlling malaria $(7,16,17)$ and more specifically their requirement to control chronic malaria (18) and for long-term sterile immunity (19). These studies suggest that vaccines for blood-stage malaria, would need to target multiple cell types including $\mathrm{CD} 8^{+} \mathrm{T}$ cells, which has not been undertaken.

\section{The Contribution of Co-signaling Pathways to Anti-malarial Immunity}

Signaling between antigen presenting cells [(APCs) including dendritic cells (DC), macrophages, and monocytes] and T cells (Figure 1) is a crucial element of adaptive $\mathrm{T}$ cell immunity which allows antigen-specific responses to be tightly regulated for effective protection against infections, while minimizing immune-mediated pathology. However, while many of these ligands and receptors are also expressed on other cells (e.g., B cells); in the interest of brevity, this review will focus on signaling between APCs and T cells.

While the interaction of the $\mathrm{T}$ cell receptor (TCR) with peptide-loaded major histocompatibility complexes (MHC) on APCs is essential for antigen-specific $\mathrm{T}$ cell activation, co-stimulatory (activating), and co-inhibitory (suppressive)

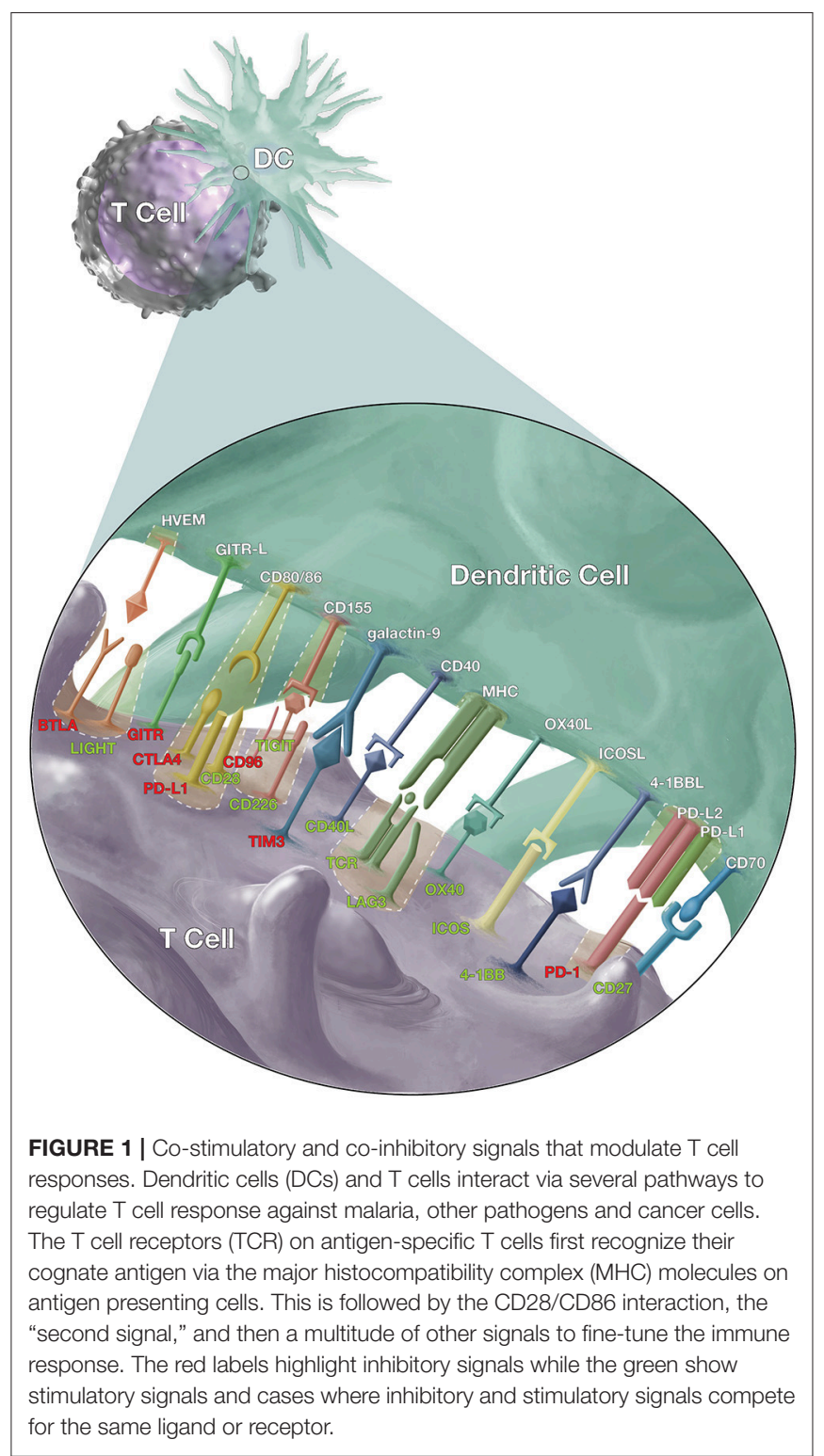

molecules determine the magnitude and type of $\mathrm{T}$ cell responses. Furthermore, these interactions also co-signal APC to modulate their functions. The requirement for co-stimulation in $\mathrm{T}$ cell activation was realized with the discovery of the function of CD28, the canonical co-stimulatory receptor $(20,21)$. Since then, a large number of co-stimulatory or co-inhibitory receptors, ligands, and counter-receptors have been discovered and studied.

The study of receptor and ligands in the context of infections, cancers and autoimmunity, has revealed that the modulation of co-signaling pathways (also known as "immune checkpoints") underpins the pathogenesis of several diseases. The balance between co-stimulatory and co-inhibitory receptor activation can have a profound effect on disease progression. Recent advances in the understanding of which immune checkpoints influence disease has led to the development of specific targeted immunotherapies that modulate immune functions to alleviate 
disease. Most immunotherapies utilize antibodies to modulate immunity and in particular, antibodies against the co-inhibitory receptors cytotoxic T-lymphocyte associated antigen-4 (CTLA-4) and PD-1 have been approved by the FDA for treatment of several cancers due to their exceptional efficacy.

Effective immunity against intracellular pathogens requires the development of an optimal $\mathrm{T}$ cell response which shows rapid proliferative potential, low apoptosis and poly-functionality (22). During acute infections, optimal functioning $\mathrm{T}$ cells clear the pathogen, eventually leading to development of robust memory $\mathrm{T}$ cells which have the ability to mount rapid recall response and re-establish poly-functional effector mechanisms upon antigen re-exposure (23). However, some diseases develop "T cell exhaustion," defined by poor effector function, sustained expression of inhibitory receptors (discussed later in detail), poor recall responses and a transcriptional state distinct from that of functional effector or memory $\mathrm{T}$ cells (23). There is increasing evidence that these inhibitory receptors affect malarial immunity. As such, the remainder of the review will look at each inhibitory / stimulatory pathway individually and discuss their roles in regulating immunity to Plasmodium infection.

\section{Programmed Cell Death Protein-1}

PD-1 (CD279) is a member of the extended CD28/CTLA4 family of $\mathrm{T}$ cell regulators (24). PD-1 is expressed on $\mathrm{T}$ cells, B cells, natural killer, dendritic cells (DCs) and activated monocytes. The engagement of PD-1 by its ligands, PD-L1 (CD274), and PD-L2 (CD273), normally inhibits T cell functions to induce tolerance and to control the expansion and function of foreign antigen-specific $\mathrm{T}$ cell-responses (25-27). PD-1 is not expressed by resting $\mathrm{T}$ cells but is induced upon activation (28). PD-1 expression on T cells is up-regulated within $24 \mathrm{~h}$ of stimulation and the effects of PD-1 ligation can be seen within a few hours (29). PD-1 needs to be engaged simultaneously with TCR signals to trigger an inhibitory signal (30). PD-1 preserves exhausted $\mathrm{T}$ cell populations from overstimulation, excessive proliferation, and terminal differentiation (31). In general, interactions between PD-1 on $\mathrm{T}$ cells and its ligand, $\mathrm{PD}-\mathrm{L} 1$, control the induction and maintenance of peripheral $\mathrm{T}$ cell tolerance during normal immune responses and negatively regulate the proliferation and the cytokine production by $\mathrm{T}$ cells (32).

Field studies in malaria-endemic areas have shown increased expression of PD-1 on $\mathrm{T}$ cells in malaria-infected individuals compared to control subjects, thus implicating PD-1 in immune evasion $(33,34)$. Significantly, flow cytometric analysis and automated multivariate clustering, has revealed more frequent expression of CTLA- 4 or PD- 1 on CD $4^{+} \mathrm{T}$ cells from children with complicated malaria compared to uncomplicated malaria (35). PD-1-deficient mice (PD-1KO) rapidly cleared chronic $P$. chabaudi malaria and developed sterile immunity unlike infections in wild type mice (18). Subsequent studies in mice showed that PD-1 also mediated loss of long-term protection against malaria (19). These studies clearly show PD-1 contributes to the pathogenesis of malaria.

PD-L1 and PD-L2, the ligands for PD-1, are expressed on a variety of cells, and their expression on DCs can down-regulate immune responses by T cells (27). Significantly, blockade of PDL1 signals by antibody, during malaria contributed to improved immunity (33). Furthermore, combined blockade of PD-L1 and Lymphocyte-activation gene 3 (LAG3) immune inhibitory molecules accelerated clearance of non-lethal $P$. yoelii bloodstage malaria by improving $\mathrm{CD} 4^{+} \mathrm{T}$ cell functions and increasing antibody titres (33). Similarly, blockade of PD-L1 during lethal $P$. berghei-induced experimental cerebral malaria (ECM) also enhanced $\mathrm{T}$ cell functions but resulted in an unfavorable outcome in this model, as improved $\mathrm{T}$ cell function promoted cerebral disease (36). These studies provide evidence that manipulating checkpoint proteins can improve immune responses.

Other studies of malaria using four mouse models revealed a novel regulatory function for PD-L2 (37). These studies showed that while PD-L1 expressed by DCs down-regulates $\mathrm{T}$ cells responses against malaria, $\mathrm{PD}-\mathrm{L} 2$ protein expressed on DCs improves immune responses by inhibiting PD-L1-PD1 interactions (37). A therapeutic role for PD-L2 was shown when multimeric form of PD-L2 given to mice infected with lethal malaria, was sufficient to clear the lethal infection and mediate survival from re-infections after several months, without additional treatment (37). Studies of healthy human volunteers before and after infection with experimental $P$. falciparum malaria, found that the expression of PD-L2 inversely correlated with the level of parasitaemia in each individual (37). Overall, this study highlighted the importance of PD-L2 expression for generating malarial immunity.

\section{CD28, CTLA-4, and CD80/CD86}

CD28 is a co-stimulatory receptor of the immunoglobulin superfamily, which activates a variety of $\mathrm{T}$ cell-activation pathways such as nuclear factor- $\mathrm{B}(\mathrm{NF}-\kappa \mathrm{B})$, nuclear factor of activated $\mathrm{T}$ cells (NFAT), BCL-XL and mammalian target of rapamycin (mTOR). These signals enhance functions associated with $\mathrm{T}$ cell activation such as IL-2 expression, proliferation, survival, and other effector mechanisms.

CD28 was found to be crucial for development of both polyclonal as well as specific antibody responses against malaria, as mice deficient in CD28 had a severe deficit in Ig-production by B cells by day 7 post-infection with $P$. chabaudi compared to WT mice (38). The effects of the CD28 deficit resulted in an inability of these mice to clear parasitemia to sub-patent levels or control re-infections. T cell proliferation was also severely compromised in CD28 deficient mice infected with $P$. chabaudi, although it was not determined whether CD28 directly influenced T cell help, B cell activation and antibody production, or both (38). Another study showed that in $\mathrm{J}_{\mathrm{H}}^{-/-}$mice which lack $\mathrm{B}$ cells, a deficiency of CD28 resulted in diminished clearance of $P$. chabaudi parasitemia, demonstrating that CD28 is crucial to both humoral and cell-mediated immunity to malaria (39).

The ligands for CD28 (B7 molecules CD80 and CD86) are expressed by APCs (40). CD80 and CD86 can also bind the inhibitory receptor, CTLA-4 (CD152) which appears on Tcell following activation $(41,42)$. The mechanism of CTLA4 function is complex with contradictory reports. CTLA-4 has a higher affinity for CD80 and CD86 than CD28 (43) and is believed to outcompete CD28 for binding to B7 ligands to 
regulate early events in T cell activation (44). CTLA-4 is also indicated to directly inhibit TCR signals, reduce IL-2 production and IL-2 receptor expression, and regulate cell cycle progression (44). It was also shown that CTLA-4 can capture B7 ligands from opposing cells by a process of trans-endocytosis resulting in impaired co-stimulation via CD28 (45). CD28 and CTLA4 binding to CD80 and CD86 thus provide a balance between activation and inhibitory signals. Significantly, PD-L1 expressed by $\mathrm{T}$ cells also binds to CD80 on DCs to inhibit T cell activation $(46,47)$. Importantly, CD28 and PD-L1 on T cells compete for CD80 binding.

Studies using $P$. chabaudi malaria have revealed that antibody blockade of CD80 binding to $\mathrm{CD} 28$ did not significantly affect the clearance of parasitemia (48). In contrast, CD86 blockade or dual blockade of CD80 and CD86 resulted in the inability of mice to clear parasitemia to sub-patent levels (48). CD86 or CD80/CD86 blockade increased IFN- $\gamma$ production while decreasing IL-4 production by ex vivo spleen cells (48). P. chabaudi-specific IgG1 antibody titres were also reduced by CD 86 blockade while early IgG2a titres were increased (48). These effects were not observed with CD80 blockade alone, but were more drastic with dual blockade. This study, along with studies on the role of $\mathrm{CD} 28$, indicate that CD86 ligation of CD28 is essential for protective humoral immunity to malaria, while cell-mediated immunity also requires $\mathrm{CD} 28$ ligation.

Increased proportions of $\mathrm{CD}^{+} \mathrm{T}$ cells express CTLA4, OX40, Glucocorticoid-induced TNFR family related gene (GITR), tumor necrosis factor alpha receptor type II (TNFRII), PD-1, LAG3, T-cell immunoglobulin and mucin-3 (TIM3) and CD69 during P. vivax $(49,50)$ and P. falciparum (51) malarias. The increased proportion of these cells did not correlate with parasite density in $P$. vivax infections, and did not persist after parasite clearance. However, simultaneous blockade of the CLTA4, PD-1, and TIM3 signaling restores the cytokine production by antigen-specific cells (50). Significantly, expression of CTLA- 4 by $\mathrm{T}$ cells is increased in children only during severe malaria (52).

Mouse studies have also shown that lethal malaria induces the production of high levels Transforming Growth Factor- $\beta$ (TGF- $\beta$ ), which is associated with delayed and blunted IFN$\gamma$ and TNF- $\alpha$ responses, failure to clear parasites, and $100 \%$ mortality (53). Mechanistic studies showed that cross-linking surface CTLA- 4 in cultures of spleen cells taken from mice infected with a lethal infection, induced TGF- $\beta$ secretion (53). In contrast, blockade of CTLA- 4 in mice was found to increase $\mathrm{T}$ cell activation and IFN- $\gamma$ production, resulting in a lower peak parasitemia during non-lethal $P$. yoelii 17XNL infections (54) and could induce cross-species protection against $P$. berghei by inhibition of regulatory $\mathrm{T}$ cells (Treg) development (55). Similarly, antibody-mediated blockade of CTLA-4 during $P$. berghei-infection in ECM-resistant $\mathrm{BALB} / \mathrm{c}$ mice resulted in higher levels of $\mathrm{T}$ cell activation, enhanced IFN- $\gamma$ production, increased intravascular arrest of both parasitised erythrocytes and $\mathrm{CD}^{+} \mathrm{T}$ cells to the brain, and augmented incidence of ECM (36). Given that $\mathrm{CD} 8^{+} \mathrm{T}$ cells facilitate cerebral disease, CTLA4 function appears to be protective against $\mathrm{CM}$, as it prevents immune-mediated pathology by restricting $\mathrm{T}$ cell activation (54, 56).

\section{Inducible T Cell COStimulator (ICOS)}

ICOS (CD278) is a CD28 homolog which regulates $\mathrm{CD}^{+}{ }^{+} \mathrm{T}$ cell activation and promotes the induction of $\mathrm{CD}^{+}$follicular Th $\left(\mathrm{T}_{\mathrm{FH}}\right)$ cells which support B cell affinity maturation within germinal centers, to generate high-affinity antibodies. When ICOS deficient mice were infected with $P$. chabaudi, primary parasitemia was significantly lower compared to control mice with a corresponding higher frequency of Th1 cells during this early phase of infection (57). $\mathrm{CD}^{+} \mathrm{T}$ cells were capable of expressing PD-1, B cell lymphoma 6, and CXCR5 during early infection, indicating $\mathrm{T}_{\mathrm{FH}}$ development was not impaired (57). However, capacity to control the chronic phase of infection, which is controlled by CD8 ${ }^{+} \mathrm{T}$ cells (18), was impaired without ICOS expression (57) indicating a role for ICOS in CD8 ${ }^{+} \mathrm{T}$ cell functions. Anti-ICOS treatment which depleted ICOS expressing $\mathrm{CD}^{+}$and $\mathrm{CD}^{+}{ }^{+}$T cells during a $P$. berghei infection resulted in a concurrent reduction in plasma IFN- $\gamma$, confirming the influence of ICOS on Th1 responses (58). Further, although ICOS deficient mice could produce similar titres of parasite-specific antibodies of most IgG isotypes, the affinity of these antibodies was much lower than that of WT mice (57). This study showed that ICOS expression has a deleterious effect on protective Th1 immunity against malaria but is necessary for maintenance of a sustained high-affinity, protective antibody responses. This was confirmed by another study where ICOS expression by CD4 ${ }^{+}$T-cells, was limited by Interferon-alpha/beta receptor alpha chain (IFNAR1)signaling to conventional DCs during P. chabaudi AS and P. yoelii $17 \mathrm{XNL}$ infections resulting in hindered resolution of infections, and impaired antibody responses (59).

ICOS expression by $\mathrm{T}$ cells may also be involved in the pathogenesis of cerebral malaria as indicated by studies with $P$. berghei which causes ECM in mice. Following P. berghei infection, mice with a deletion in the Fc receptor, Fc $\gamma$ RIIB, or transgenic mice overexpressing toll like receptor 7 (TLR-7) had lower levels of cerebral pathology than WT mice, but were unable to control parasitemia (60). T cells from Fc $\gamma$ RIIB deficient mice had uniformly intermediate levels of ICOS expression, while WT animals had two populations consisting of ICOS-high andlow $\mathrm{T}$ cells with the former being associated with better IFN$\gamma$ responses. This study indicated that ICOS plays a part in modulating Th1 immunity which supports cerebral pathology in malaria.

\section{HVEM/ /BTLA}

The B and T lymphocyte attenuator (BTLA; CD272) and tumor necrosis factor superfamily member 14 (TNFSF14; also known as LIGHT; CD258) compete for interaction with herpesvirus entry mediator (HVEM; also known as tumor necrosis factor receptor superfamily member 14; CD270) and form a part of a complex family of co-signaling molecules. Ligation of LIGHT by HVEM is costimulatory, while BTLA-HVEM binding is co-inhibitory $(61,62)$. HVEM is expressed by many cells (e.g., hematopoietic, endothelial and epithelial cells), while the LIGHT is expressed on both innate and adaptive immune cells, and BTLA is expressed on naïve $\mathrm{T}$ and $\mathrm{B}$ cells and is further upregulated on activation.

Following infection of mice with cerebral malaria-causing $P$. berghei, both $\mathrm{CD}^{+}$and $\mathrm{CD} 8^{+} \mathrm{T}$ cells in the spleen exhibited 
increased BTLA expression (63). Agonizing this inhibitory receptor with an antibody reduced $\mathrm{T}$ cell infiltration in the brain. The $\mathrm{T}$ cells that did infiltrate the brain were less activated and produced less inflammatory cytokines. This effect of BTLA on cerebral pathology was only observed if the antibody was administered within the first 2 days of infection, indicating that the effect was due to reduced T cell priming. In contrast, BTLA knockout mice infected with non-lethal P. yoelii, exhibited strongly reduced parasitemia and cleared the infection earlier compared with wild-type mice (64). Protection was associated increased pro-inflammatory cytokine production by $\mathrm{T}$ cells, without the previously observed pathology (64). Thus, BTLAHVEM interaction is relevant to malaria but while blockade would be beneficial to controlling parasitemia, it could increase the incidence of cerebral malaria. Of note, genetic variants of BTLA in humans, influence susceptibility to severe chronic hepatitis B (65), which could influence susceptibility to cerebral malaria.

Selective blocking of LIGHT and HVEM signaling does not protect mice from $P$. berghei ECM (66). However, LIGHT also binds to lymphotoxin $\beta$ receptor (LT $\beta R$ ) besides HVEM (67). Blockade of LIGHT and LT $\beta$ R signaling pathway early during $P$. berghei infection lead to increased splenic monocytes/macrophages, while blocking later in infection leads to reduced systemic cytokines, thus protecting mice from ECM (66). Thus, indicating that both BTLA and LIGHT are important immune regulators during experimental malaria.

\section{GITR}

GITR is another member of the TNFR superfamily (TNFRSF) (68). GITR is expressed in lymphoid tissues and is involved in controlling activated $\mathrm{T}$ cells. While resting $\mathrm{T}$ cells express low levels of GITR that increase upon activation, $\mathrm{CD} 4{ }^{+} \mathrm{CD} 25^{+}$Treg cells express high levels (69). Agonist antibody against GITR enhances anti-CD3-induced proliferation of $\mathrm{T}$ lymphocytes, induce proliferation in anergic $\mathrm{CD} 4{ }^{+} \mathrm{CD} 25^{+}$Tregs and enhances proliferation of $\mathrm{CD} 4^{+} \mathrm{CD} 25^{-}$responder $\mathrm{T}$ lymphocytes (70).

Multiple field studies have also implicated Tregs in the pathogenesis of malaria. Specifically, surface expression of GITR and intracellular expression of CTLA-4 were significantly upregulated in Tregs from $P$. vivax-infected individuals, with a positive association between either absolute numbers of $\mathrm{CD} 4{ }^{+} \mathrm{CD} 25^{+} \mathrm{FoxP}^{+} \mathrm{GITR}^{+}$or $\mathrm{CD} 4{ }^{+} \mathrm{CD} 25^{+} \mathrm{FoxP}^{+}{ }^{+} \mathrm{CTLA}-4^{+}$ and parasite load (71).

A role for Treg cells in mediating lethality of malaria was shown when mice survived lethal P. yoelii XL infections following depletion of Tregs (72). These Tregs were shown to inhibit the activation of effector T cells. However, Tregs did not affect the course of non-lethal P. yoelii 17XNL infections (72). Given that GITR is highly expressed by Tregs and supports their suppressive functions, an agonist antibody against GITR was tested during lethal and non-lethal malaria. However, GITR-signaling did not suppress Tregs during the lethal $P$. yoelii XL infection, indicating that Tregs developed a GITR-resistant mechanism during this infection (73).

In contrast, anti-GITR antibodies could partially reverse Treg-functions in $P$. berghei infections (74). Mice infected with
P. berghei were shown to develop $\gamma \delta \mathrm{T}$ cells which secrete inflammatory cytokines IFN- $\gamma$ and IL-17, but Tregs suppress expansion and abolish the effector function of antigen-activated $\gamma \delta$ T cells (74). This suppressive effect of Tregs, could be partially reversed by using a monoclonal antibody to GITR. Overall, these studies suggest GITR may control only a subset of Tregs during malaria.

\section{OX40}

Tumor necrosis factor receptor superfamily, member 4 (TNFRSF4 or CD134), also known as OX40 receptor, is a co-stimulatory receptor expressed on activated $\mathrm{CD} 4^{+}$and $\mathrm{CD} 8^{+}$ $\mathrm{T}$ cells as well as a number of other lymphoid and non-lymphoid cells. The ligand for OX40, OX40L, is upregulated on APC following activation. Signals to OX40 promote expansion and survival of antigen-specific T cells (75).

Malaria patients and Plasmodium-infected rodents express OX40 predominantly on $\mathrm{CD}^{+} \mathrm{T}$ cells. Treatment of mice with an agonistic antibody against OX40 enhances helper $\mathrm{CD} 4^{+} \mathrm{T}$ cell activity, humoral immunity, and parasite clearance in during non-lethal malarial infections (76). OX40, is also upregulated on $\mathrm{CD}^{+}$and $\mathrm{CD}^{+} \mathrm{T}$ cells in the brain vasculature during ECM (77). Thus, while targeting OX40 may seems to be an attractive means to improve malarial immunity, previous studies showed improving immunity exacerbates ECM (36). Furthermore, agonizing OX40 and blocking PD-L1 during malaria without the complication of ECM, caused excessive IFN- $\gamma$ responses which inhibited Tfh development required to clear the parasite (76). However, ligation of OX40 during nonlethal P. yoelii infection can increase the number of parasitespecific Th1-like memory cells which also exhibit phenotypic and functional features of Tfh cells during recall responses (78). Similarly, targeting OX40 with antibodies in conjunction with vaccination can also improve expansion of antigen-experienced effector $\mathrm{CD}^{+}$and $\mathrm{CD} 4^{+} \mathrm{T}$ cells and commitment protection (79). Overall, OX40 has a complicated function requiring further investigation, especially in the context of malaria.

\section{TIM3}

TIM3 (also known as Hepatitis A virus cellular receptor 2), is expressed on $\mathrm{CD}^{+} \mathrm{Th} 1$ and $\mathrm{CD} 8^{+} \mathrm{T}$ cells. Galectin-9 was suggested to be a ligand for TIM3 (80) although this has been disputed for human T cells (81). TIM3 also binds phosphatidylserine (82). Ligation of TIM3 results in a selective loss of IFN- $\gamma$-producing cells and suppression of Th1-mediated autoimmunity (80).

TIM3 expression is significantly increased on a variety of $\mathrm{T}$ cells from $P$. falciparum-infected patients $(83,84)$. There are two main types of $\gamma \delta \mathrm{T}$ cells found in human blood, Vdeltal and Vdelta2, and numbers of the latter increase significantly following $P$. falciparum infection in naive adults, but are lost in children following repeated exposure to malaria (83). The secretion of pro-inflammatory cytokines by these $\mathrm{T}$ cells was inversely associated with parasitemia and expression of TIM3 (73). Similarly, TIM3 expression is also significantly increased in mice infected with $P$. berghei $(84,85)$. Experimental models have shown upregulation of TIM3 during malaria leads to 
lymphocyte exhaustion which can be reversed with blockade of TIM3, resulting in the accelerated clearance of parasites and relief from the symptoms of P. berghi-mediated ECM (84). The role of TIM3 appears to be significant, requiring further investigation.

\section{CD40}

CD40 is a costimulatory protein found on APCs, which is required for co-stimulation via CD154 (CD40L) on T cells. As CD40 is an essential component of Th1 and humoral immune responses, studies have looked for polymorphisms which may explain differences in susceptibility to malaria. Field studies in Mali have revealed a marginal susceptibility effect for the CD40L+220C allele from life-threatening malaria (86) but no effect on susceptibility to $P$. vivax in Brazil (87). However, from a functional viewpoint, $\gamma \delta$ T cells are essential for clearance of the malarial parasites as they have key role in dendritic cell activation via CD40 ligand expression and IFN- $\gamma$ production $(88,89)$. As agonistic antibodies to improve immunity are being developed for the treatment of cancer, these could play a role in the future.

\section{CONCLUSION}

Malaria is a complex disease and the failure to produce an efficacious vaccine indicates immune suppression mechanisms are impeding protection. The large number of studies cited in this review confirm an important role for immune checkpoint

\section{REFERENCES}

1. Schwartz L, Brown GV, Genton B, Moorthy VS. A review of malaria vaccine clinical projects based on the WHO rainbow table. Malar J. (2012) 11:11. doi: 10.1186/1475-2875-11-11

2. Crompton PD, Pierce SK, Miller LH. Advances and challenges in malaria vaccine development. J Clin Invest. (2010) 120:4168-78. doi: 10.1172/JCI44423

3. Cohen S, McGregor I, Carrington S. Gamma-globulin and acquired immunity to human malaria. Nature (1961) 192:733-7. doi: 10.1038/192733a0

4. Su Z, Stevenson MM. IL-12 is required for antibody-mediated protective immunity against blood-stage Plasmodium chabaudi AS malaria infection in mice. J Immunol. (2002) 168:1348-55. doi: 10.4049/jimmunol.168.3.1348

5. Perez-Mazliah D, Ng DH, Freitas do Rosario AP, McLaughlin S, MastelicGavillet B, Sodenkamp J, et al. Disruption of IL-21 signaling affects T cell-B cell interactions and abrogates protective humoral immunity to malaria. PLoS Pathog. (2015) 11:e1004715. doi: 10.1371/journal.ppat.1004715

6. Mota MM, Brown KN, Holder AA, Jarra W. Acute Plasmodium chabaudi chabaudi malaria infection induces antibodies which bind to the surfaces of parasitized erythrocytes and promote their phagocytosis by macrophages in vitro. Infect Immun. (1998) 66:4080-6.

7. Podoba JE, Stevenson MM. CD4+ and CD8+ T lymphocytes both contribute to acquired immunity to blood-stage Plasmodium chabaudi AS. Infect Immun. (1991) 59:51-8.

8. Langhorne J, Gillard S, Simon B, Slade S, Eichmann K. Frequencies of CD4+ T cells reactive with Plasmodium chabaudi chabaudi: distinct response kinetics for cells with Th1 and Th2 characteristics during infection. Int Immunol. (1989) 1:416-24. doi: 10.1093/intimm/1.4.416

9. Stevenson MM, Tam MF. Differential induction of helper $\mathrm{T}$ cell subsets during blood-stage Plasmodium chabaudi AS infection in resistant and susceptible mice. Clin Exp Immunol. (1993) 92:77-83. doi: 10.1111/j.1365-2249.1993.tb05951.x

10. Luty AJ, Lell B, Schmidt-Ott R, Lehman LG, Luckner D, Greve B, et al. Interferon-gamma responses are associated with resistance to reinfection with Plasmodium falciparum in young African children. J Infect Dis. (1999) 179:980-8. doi: 10.1086/314689 proteins in the pathogenesis malaria. However, the exceptional cost and potential side effects know to occur with immune checkpoint cancer treatments, as well potential exacerbation of cerebral malaria, has impeded any attempt to progress such treatments for malaria. Nevertheless, given rising drug resistance, difficulties in generating an efficacious vaccine for malaria and that some treatments such as soluble PD-L2 generate longterm protection with a reduction in the incidence of cerebral malaria, indicate that checkpoint blockade needs to be further explored.

\section{AUTHOR CONTRIBUTIONS}

All authors listed have made a substantial, direct and intellectual contribution to the work, and approved it for publication.

\section{FUNDING}

The authors are supported by grants from The National Health and Medical Research Council and QIMR Berghofer Medical Research Institute.

\section{ACKNOWLEDGMENTS}

The authors sincerely thank Tal Bavli, Madeleine Flynn and Ciara O'Hanlon for the design and implementation of the Figure.

11. Muxel SM, Freitas do Rosario AP, Zago CA, Castillo-Mendez SI, Sardinha LR, Rodriguez-Malaga SM, et al. The spleen CD4+ T cell response to blood-stage Plasmodium chabaudi malaria develops in two phases characterized by different properties. PLoS ONE (2011) 6:e22434. doi: 10.1371/journal.pone.0022434

12. Jacobs P, Radzioch D, Stevenson MM. A Th1-associated increase in tumor necrosis factor alpha expression in the spleen correlates with resistance to blood-stage malaria in mice. Infect Immun. (1996) 64:535-41.

13. Belnoue E, Kayibanda M, Vigario AM, Deschemin JC, van Rooijen N, Viguier $\mathrm{M}$, et al. On the pathogenic role of brain-sequestered alphabeta CD8+ $\mathrm{T}$ cells in experimental cerebral malaria. J Immunol. (2002) 169:6369-75. doi: 10.4049/jimmunol.169.11.6369

14. Mitchell AJ, Hansen AM, Hee L, Ball HJ, Potter SM, Walker JC, et al. Early cytokine production is associated with protection from murine cerebral malaria. Infect Immun. (2005) 73:5645-53. doi: 10.1128/IAI.73.9.5645-5653.2005

15. Beattie L, Engwerda CR, Wykes M, Good MF. CD8+ T lymphocytemediated loss of marginal metallophilic macrophages following infection with Plasmodium chabaudi chabaudi AS. J Immunol. (2006) 177:2518-26. doi: 10.4049/jimmunol.177.4.2518

16. Imai T, Shen J, Chou B, Duan X, Tu L, Tetsutani K, et al. Involvement of $\mathrm{CD} 8+\mathrm{T}$ cells in protective immunity against murine blood-stage infection with Plasmodium yoelii 17XL strain. Eur J Immunol. (2010) 40:1053-61. doi: 10.1002/eji.200939525

17. Imai $\mathrm{T}$, Ishida $H$, Suzue $K$, Hirai $M$, Taniguchi $T$, Okada $H$, et al. CD8(+) $T$ cell activation by murine erythroblasts infected with malaria parasites. Sci Rep. (2013) 3:1572. doi: 10.1038/srep01572

18. Horne-Debets JM, Faleiro R, Karunarathne DS, Liu XQ, Lineburg KE, Poh $\mathrm{CM}$, et al. PD-1 dependent exhaustion of CD8(+) $\mathrm{T}$ cells drives chronic malaria. Cell Rep. (2013) 5:1204-13. doi: 10.1016/j.celrep.2013.11.002

19. Horne-Debets JM, Karunarathne DS, Faleiro RJ, Poh CM, Renia L, Wykes MN. Mice lacking programmed cell death-1 show a role for CD8(+) T cells in long-term immunity against blood-stage malaria. Sci Rep. (2016) 6:26210. doi: 10.1038/srep26210

20. June $\mathrm{CH}$, Ledbetter JA, Gillespie MM, Lindsten $\mathrm{T}$, Thompson CB. T-cell proliferation involving the CD28 pathway is associated with 
cyclosporine-resistant interleukin 2 gene expression. Mol Cell Biol. (1987) 7:4472-81. doi: 10.1128/MCB.7.12.4472

21. Mueller DL, Jenkins M, Schwartz R. Clonal expansion versus functional clonal inactivation: a costimulatory signalling pathway determines the outcome of T cell antigen receptor occupancy. Annu Rev Immunol. (1989) 7:445-80. doi: 10.1146/annurev.iy.07.040189.002305

22. Lukens JR, Cruise MW, Lassen MG, Hahn YS. Blockade of PD$1 / \mathrm{B} 7-\mathrm{H} 1$ interaction restores effector $\mathrm{CD} 8+\mathrm{T}$ cell responses in a hepatitis C virus core murine model. J Immunol. (2008) 180:4875-84. doi: $10.4049 /$ jimmunol.180.7.4875

23. Wherry EJ. T cell exhaustion. Nat Immunol. (2011) 12:492-9. doi: 10.1038/ni.2035

24. Ishida Y, Agata Y, Shibahara K, Honjo T. Induced expression of PD-1, a novel member of the immunoglobulin gene superfamily, upon programmed cell death. EMBO J. (1992) 11:3887-95. doi: 10.1002/j.1460-2075.1992.tb05481.x

25. Latchman Y, Wood CR, Chernova T, Chaudhary D, Borde M, Chernova I, et al. PD-L2 is a second ligand for PD-1 and inhibits T cell activation. Nat Immunol. (2001) 2:261-8. doi: 10.1038/85330

26. Martin-Orozco N, Wang YH, Yagita H, Dong C. Cutting edge: Programmed death (PD) ligand-1/PD-1 interaction is required for CD8+ T cell tolerance to tissue antigens. J Immunol. (2006) 177:8291-5. doi: 10.4049/jimmunol.177.12.8291

27. Brown JA, Dorfman DM, Ma FR, Sullivan EL, Munoz O, Wood CR, et al. Blockade of programmed death-1 ligands on dendritic cells enhances $\mathrm{T}$ cell activation and cytokine production. J Immunol. (2003) 170:1257-66. doi: 10.4049/jimmunol.170.3.1257

28. Agata $\mathrm{Y}$, Kawasaki A, Nishimura H, Ishida $\mathrm{Y}$, Tsubata T, Yagita $\mathrm{H}$, et al. Expression of the PD-1 antigen on the surface of stimulated mouse $\mathrm{T}$ and $\mathrm{B}$ lymphocytes. Int Immunol. (1996) 8:765-72. doi: 10.1093/intimm/8.5.765

29. Chemnitz JM, Parry RV, Nichols KE, June CH, Riley JL. SHP-1 and SHP-2 associate with immunoreceptor tyrosine-based switch motif of programmed death 1 upon primary human $\mathrm{T}$ cell stimulation, but only receptor ligation prevents T cell activation. J Immunol. (2004) 173:945-54. doi: 10.4049/jimmunol.173.2.945

30. Sharpe AH, Wherry EJ, Ahmed R, Freeman GJ. The function of programmed cell death 1 and its ligands in regulating autoimmunity and infection. Nat Immunol. (2007) 8:239-45. doi: 10.1038/ni1443

31. Odorizzi PM, Pauken KE, Paley MA, Sharpe A, Wherry EJ. Genetic absence of PD-1 promotes accumulation of terminally differentiated exhausted CD8+ T cells. J Exp Med. (2015) 212:1125-37. doi: 10.1084/jem.20142237

32. Keir ME, Liang SC, Guleria I, Latchman YE, Qipo A, Albacker LA, et al. Tissue expression of PD-L1 mediates peripheral T cell tolerance. J Exp Med. (2006) 203:883-95. doi: 10.1084/jem.20051776

33. Butler NS, Moebius J, Pewe LL, Traore B, Doumbo OK, Tygrett LT, et al. Therapeutic blockade of PD-L1 and LAG-3 rapidly clears established blood-stage Plasmodium infection. Nat Immunol. (2012) 13:18895. doi: 10.1038/ni.2180

34. Illingworth J, Butler NS, Roetynck S, Mwacharo J, Pierce SK, Bejon P, et al. Chronic exposure to Plasmodium falciparum is associated with phenotypic evidence of B and T cell exhaustion. J Immunol. (2013) 190:1038-47. doi: 10.4049/jimmunol.1202438

35. Abel A, Steeg C, Aminkiah F, Addai-Mensah O, Addo M, Gagliani N, et al. Differential expression pattern of co-inhibitory molecules on CD4(+) T cells in uncomplicated versus complicated malaria. Sci Rep. (2018) 8:4789. doi: 10.1038/s41598-018-22659-1

36. Hafalla JC, Claser C, Couper KN, Grau GE, Renia L, de Souza JB, et al. The CTLA-4 and PD-1/PD-L1 inhibitory pathways independently regulate host resistance to plasmodium-induced acute immune pathology. PLoS Pathog. (2012) 8:e1002504. doi: 10.1371/journal.ppat.1002504

37. Karunarathne DS, Horne-Debets JM, Huang JX, Faleiro R, Leow CY, Amante F, et al. Programmed death-1 Ligand 2-mediated regulation of the PD-L1 to PD-1 axis is essential for establishing CD4(+) T cell immunity. Immunity (2016) 45:333-45. doi: 10.1016/j.immuni.2016.07.017

38. Elias RM, Sardinha LR, Bastos KR, Zago CA, da Silva AP, Alvarez JM, et al. Role of $\mathrm{CD} 28$ in polyclonal and specific $\mathrm{T}$ and $\mathrm{B}$ cell responses required for protection against blood stage malaria. J Immunol. (2005) 174:790-9. doi: 10.4049/jimmunol.174.2.790
39. Rummel T, Batchelder J, Flaherty P, LaFleur G, Nanavati P, Burns JM, et al. CD28 costimulation is required for the expression of T-celldependent cell-mediated immunity against blood-stage Plasmodium chabaudi malaria parasites. Infect Immun. (2004) 72:5768-74. doi: 10.1128/IAI.72.10.5768-5774.2004

40. Subauste CS, de Waal Malefyt R, Fuh F. Role of CD80 (B7.1) and CD86 (B7.2) in the immune response to an intracellular pathogen. J Immunol. (1998) 160:1831-40.

41. Caux C, Vanbervliet B, Massacrier C, Azuma M, Okumura K, Lanier LL, et al. B70/B7-2 is identical to CD86 and is the major functional ligand for CD28 expressed on human dendritic cells. J Exp Med. (1994) 180:1841-7. doi: 10.1084 /jem.180.5.1841

42. Loser K, Scherer A, Krummen MB, Varga G, Higuchi T, Schwarz T, et al. An important role of CD80/CD86-CTLA-4 signaling during photocarcinogenesis in mice. J Immunol. (2005) 174:5298-305. doi: 10.4049/jimmunol.174.9.5298

43. Linsley PS, Ledbetter JA. The role of the CD28 receptor during T cell responses to antigen. Annu Rev Immunol. (1993) 11:191-212. doi: 10.1146/annurev.iy.11.040193.001203

44. Brunner MC, Chambers CA, Chan FK, Hanke J, Winoto A, Allison JP. CTLA4-mediated inhibition of early events of T cell proliferation. J Immunol. (1999) 162:5813-20.

45. Qureshi OS, Zheng Y, Nakamura K, Attridge K, Manzotti C, Schmidt EM, et al. Trans-endocytosis of CD80 and CD86: a molecular basis for the cell-extrinsic function of CTLA-4. Science (2011) 332:600-3. doi: 10.1126/science.1202947

46. Butte MJ, Pena-Cruz V, Kim MJ, Freeman GJ, Sharpe AH. Interaction of human PD-L1 and B7-1. Mol Immunol. (2008) 45:3567-72. doi: 10.1016/j.molimm.2008.05.014

47. Butte MJ, Keir ME, Phamduy TB, Sharpe AH, Freeman GJ. Programmed death-1 ligand 1 interacts specifically with the B7-1 costimulatory molecule to inhibit $\mathrm{T}$ cell responses. Immunity (2007) 27:111-22. doi: 10.1016/j.immuni.2007.05.016

48. Taylor-Robinson AW, Smith EC. Modulation of experimental blood stage malaria through blockade of the $\mathrm{B} 7 / \mathrm{CD} 28 \mathrm{~T}$-cell costimulatory pathway. Immunology (1999) 96:498-504. doi: 10.1046/j.1365-2567.1999.00718.x

49. Goncalves-Lopes RM, Lima NF, Carvalho KI, Scopel KK, Kallas EG, Ferreira MU. Surface expression of inhibitory (CTLA-4) and stimulatory (OX40) receptors by $\mathrm{CD} 4+$ regulatory $\mathrm{T}$ cell subsets circulating in human malaria. Microbes Infect. (2016) 18:639-48. doi: 10.1016/j.micinf.2016.06.003

50. Costa PA, Leoratti FM, Figueiredo MM, Tada MS, Pereira DB, Junqueira $\mathrm{C}$, et al. Induction of inhibitory receptors on $\mathrm{T}$ cells during plasmodium vivax malaria impairs cytokine production. J Infect Dis. (2015) 212:1999-2010. doi: 10.1093/infdis/jiv306

51. Schlotmann T, Waase I, Julch C, Klauenberg U, Muller-Myhsok B, Dietrich M, et al. $\mathrm{CD} 4$ alphabeta $\mathrm{T}$ lymphocytes express high levels of the T lymphocyte antigen CTLA-4 (CD152) in acute malaria. J Infect Dis. (2000) 182:367-70. doi: $10.1086 / 315690$

52. Braun N, Marfo Y, Von Gartner C, Burchard GD, Zipfel PF, Browne NE, et al. CTLA-4 positive $\mathrm{T}$ cells in contrast to procalcitonin plasma levels discriminate between severe and uncomplicated Plasmodium falciparum malaria in Ghanaian children. Trop Med Int Health (2003) 8:1018-24. doi: 10.1046/j.1360-2276.2003.01128.x

53. Omer FM, de Souza JB, Riley EM. Differential induction of TGF-beta regulates proinflammatory cytokine production and determines the outcome of lethal and nonlethal Plasmodium yoelii infections. J Immunol. (2003) 171:5430-6. doi: 10.4049/jimmunol.171.10.5430

54. Lepenies B, Gaworski I, Tartz S, Langhorne J, Fleischer B, Jacobs T. CTLA-4 blockade differentially influences the outcome of non-lethal and lethal Plasmodium yoelii infections. Microbes Infect. (2007) 9:687-94. doi: 10.1016/j.micinf.2007.02.013

55. Kurup SP, Obeng-Adjei N, Anthony SM, Traore B, Doumbo OK, Butler NS, et al. Regulatory $\mathrm{T}$ cells impede acute and long-term immunity to blood-stage malaria through CTLA-4. Nat Med. (2017) 23:1220-5. doi: 10.1038/nm.4395

56. Jacobs T, Graefe SE, Niknafs S, Gaworski I, Fleischer B. Murine malaria is exacerbated by CTLA-4 blockade. I Immunol. (2002) 169:2323-9. doi: 10.4049/jimmunol.169.5.2323

57. Wikenheiser DJ, Ghosh D, Kennedy B, Stumhofer JS. The costimulatory molecule ICOS regulates host Th1 and Follicular Th cell differentiation in 
response to Plasmodium chabaudi chabaudi AS infection. J Immunol. (2016) 196:778-91. doi: 10.4049/jimmunol.1403206

58. Jogdand GM, Sengupta S, Bhattacharya G, Singh SK, Barik PK, Devadas S. Inducible costimulator expressing $\mathrm{T}$ cells promote parasitic growth during blood stage Plasmodium berghei ANKA infection. Front Immunol. (2018) 9:1041. doi: 10.3389/fimmu.2018.01041

59. Sebina I, James KR, Soon MS, Fogg LG, Best SE, Labastida Rivera F, et al. IFNAR1-signalling obstructs ICOS-mediated humoral immunity during nonlethal blood-stage plasmodium infection. PLoS Pathog. (2016) 12:e1005999. doi: 10.1371/journal.ppat.1005999

60. Waisberg M, Tarasenko T, Vickers BK, Scott BL, Willcocks LC, MolinaCruz A, et al. Genetic susceptibility to systemic lupus erythematosus protects against cerebral malaria in mice. Proc Natl Acad Sci USA. (2011) 108:1122-7. doi: 10.1073/pnas.1017996108

61. Cai G, Anumanthan A, Brown JA, Greenfield EA, Zhu B, Freeman GJ. CD160 inhibits activation of human CD4+ $\mathrm{T}$ cells through interaction with herpesvirus entry mediator. Nat Immunol. (2008) 9:176-85. doi: $10.1038 /$ ni1554

62. Cai G, Freeman GJ. The CD160, BTLA, LIGHT/HVEM pathway: a bidirectional switch regulating T-cell activation. Immunol Rev. (2009) 229:244-58. doi: 10.1111/j.1600-065X.2009.00783.x

63. Lepenies B, Pfeffer K, Hurchla MA, Murphy TL, Murphy KM, Oetzel $\mathrm{J}$, et akl. Ligation of $\mathrm{B}$ and $\mathrm{T}$ lymphocyte attenuator prevents the genesis of experimental cerebral malaria. J Immunol. (2007) 179:4093-100. doi: 10.4049/jimmunol.179.6.4093

64. Adler G, Steeg C, Pfeffer K, Murphy TL, Murphy KM, Langhorne J, et al. $\mathrm{B}$ and $\mathrm{T}$ lymphocyte attenuator restricts the protective immune response against experimental malaria. J Immunol. (2011) 187:5310-9. doi: 10.4049/jimmunol.1101456

65. Tang J, Fei J, Gu C, Liu W, Li M, Zhou C. The influence of B and T lymphocyte attenuator genetic variants on susceptibility to chronic Hepatitis B virus infection. Cell Physiol Biochem. (2018) 45:2540-7. doi: 10.1159/000488272

66. Randall LM, Amante FH, Zhou Y, Stanley AC, Haque A, Rivera F, et al. Cutting edge: selective blockade of LIGHT-Lymphotoxin $\beta$ receptor signaling protects mice from experimental cerebral malaria caused by Plasmodium berghei ANKA. J Immunol. (2008) 181:7458-62. doi: 10.4049/jimmunol.181.11.7458

67. Mauri DN, Ebner R, Montgomery RI, Kochel KD, Cheung TC, Yu GL, et al. LIGHT, a new member of the TNF superfamily, and lymphotoxin alpha are ligands for herpesvirus entry mediator. Immunity (1998) 8:21-30. doi: 10.1016/S1074-7613(00)80455-0

68. Nocentini G, Giunchi L, Ronchetti S, Krausz LT, Bartoli A, Moraca R, et al. A new member of the tumor necrosis factor/nerve growth factor receptor family inhibits T cell receptor-induced apoptosis. Proc Natl Acad Sci USA. (1997) 94:6216-21.

69. Ephrem A, Epstein AL, Stephens GL, Thornton AM, Glass D, Shevach EM. Modulation of Treg cells/T effector function by GITR signaling is contextdependent. Eur J Immunol. (2013) 43:2421-9. doi: 10.1002/eji.201343451

70. Ronchetti S, Zollo O, Bruscoli S, Agostini M, Bianchini R, Nocentini G, et al. Frontline: GITR, a member of the TNF receptor superfamily, is costimulatory to mouse T lymphocyte subpopulations. Eur J Immunol. (2004) 34:613-22. doi: 10.1002/eji.200324804

71. Bueno LL, Morais CG, Araujo FF, Gomes JA, Correa-Oliveira R, Soares IS, et al. Plasmodium vivax: induction of CD4+CD25+FoxP3+ regulatory T cells during infection are directly associated with level of circulating parasites. PLoS ONE (2010) 5:e9623. doi: 10.1371/journal.pone.0009623

72. Hisaeda H, Maekawa Y, Iwakawa D, Okada H, Himeno K, Kishihara K, et al. Escape of malaria parasites from host immunity requires CD4+ CD25+ regulatory T cells. Nat Med. (2004) 10:29-30. doi: 10.1038/nm975

73. Hisaeda H, Hamano S, Mitoma-Obata C, Tetsutani K, Imai T, Waldmann H, et al. Resistance of regulatory $\mathrm{T}$ cells to glucocorticoid-induced [corrected] TNFR family-related protein (GITR) during Plasmodium yoelii infection. Eur J Immunol. (2005) 35:3516-24. doi: 10.1002/eji.200526073

74. Gonçalves-Sousa N, Ribot JC, deBarros A, Correia DV, Caramalho Í, SilvaSantos B. Inhibition of murine $\gamma \delta$ lymphocyte expansion and effector function by regulatory $\alpha \beta \mathrm{T}$ cells is cell-contact-dependent and sensitive to GITR modulation. Eur J Immunol. (2010) 40:61-70. doi: 10.1002/eji.200939715

75. Gramaglia I, Jember A, Pippig SD, Weinberg AD, Killeen N, Croft M. The OX40 costimulatory receptor determines the development of CD4 memory by regulating primary clonal expansion. J Immunol. (2000) 165:3043-50. doi: 10.4049/jimmunol.165.6.3043

76. Zander RA, Obeng-Adjei N, Guthmiller JJ, Kulu DI, Li J, Ongoiba A, et al. PD-1 Co-inhibitory and OX40 co-stimulatory crosstalk regulates helper T cell differentiation and anti-plasmodium humoral immunity. Cell Host Microbe (2015) 17:628-41. doi: 10.1016/j.chom.2015.03.007

77. Oakley MS, Majam V, Mahajan B, Gerald N, Anantharaman V, Ward $\mathrm{JM}$, et al. Pathogenic roles of CD14, galectin-3, and OX40 during experimental cerebral malaria in mice. PLoS ONE (2009) 4:e6793. doi: 10.1371/journal.pone.0006793

78. Zander RA, Vijay R, Pack AD, Guthmiller JJ, Graham AC, Lindner SE, et al. Th1-like Plasmodium-specific memory $\mathrm{CD} 4(+) \mathrm{T}$ cells support humoral immunity. Cell Rep. (2017) 21:1839-52. doi: 10.1016/j.celrep.2017. 10.077

79. Othman AS, Franke-Fayard BM, Imai T, van der Gracht ETI, Redeker A, Salman AM, et al. OX40 stimulation enhances protective immune responses induced after vaccination with attenuated malaria parasites. Front Cell Infect Microbiol. (2018) 8:247. doi: 10.3389/fcimb.2018.00247

80. Zhu C, Anderson AC, Schubart A, Xiong H, Imitola J, Khoury SJ, et al. The Tim-3 ligand galectin-9 negatively regulates T helper type 1 immunity. Nat Immunol. (2005) 6:1245-52. doi: 10.1038/ni1271

81. Leitner J, Rieger A, Pickl WF, Zlabinger G, Grabmeier-Pfistershammer K, Steinberger P. TIM-3 does not act as a receptor for galectin-9. PLoS Pathog. (2013) 9:e1003253. doi: 10.1371/journal.ppat.1003253

82. DeKruyff RH, Bu X, Ballesteros A, Santiago C, Chim YL, Lee HH, et al. T cell/transmembrane, Ig, and mucin-3 allelic variants differentially recognize phosphatidylserine and mediate phagocytosis of apoptotic cells. J Immunol. (2010) 184:1918-30. doi: 10.4049/jimmunol.0903059

83. Jagannathan P, Lutwama F, Boyle MJ, Nankya F, Farrington LA, McIntyre TI, et al. Vdelta2 $+\mathrm{T}$ cell response to malaria correlates with protection from infection but is attenuated with repeated exposure. Sci Rep. (2017) 7:11487. doi: 10.1038/s41598-017-10624-3

84. Hou N, Zou Y, Piao X, Liu S, Wang L, Li S, et al. T-cell immunoglobulinand mucin-domain-containing molecule 3 signaling blockade improves cell-mediated immunity against malaria. J Infect Dis. (2016) 214:1547-56. doi: 10.1093/infdis/jiw428

85. Huang B, Liu M, Huang S, Wu B, Guo H, Su XZ, et al. Expression of Tim1 and Tim-3 in Plasmodium berghei ANKA infection. Parasitol Res. (2013) 112:2713-9. doi: 10.1007/s00436-013-3442-z

86. Toure O, Konate S, Sissoko S, Niangaly A, Barry A, Sall AH, et al. Candidate polymorphisms and severe malaria in a Malian population. PLoS ONE (2012) 7:e43987. doi: 10.1371/journal.pone.0043987

87. Capobianco MP, Cassiano GC, Furini AA, Storti-Melo LM, Pavarino EC, Galbiatti AL, et al. No evidence for association of the CD40, CD40L and BLYS polymorphisms, B-cell co-stimulatory molecules, with Brazilian endemic Plasmodium vivax malaria. Trans R Soc Trop Med Hyg. (2013) 107:377-83. doi: $10.1093 /$ trstmh/trt031

88. Inoue $\mathrm{S}$, Niikura $\mathrm{M}$, Takeo $\mathrm{S}$, Mineo $\mathrm{S}$, Kawakami $\mathrm{Y}$, Uchida $\mathrm{A}$, et al. Enhancement of dendritic cell activation via CD40 ligandexpressing gammadelta $\mathrm{T}$ cells is responsible for protective immunity to Plasmodium parasites. Proc Natl Acad Sci USA. (2012) 109:12129-34. doi: 10.1073/pnas.1204480109

89. Inoue SI, Niikura M, Asahi H, Iwakura Y, Kawakami Y, Kobayashi F. Preferentially expanding Vgammal $(+)$ gammadelta $\mathrm{T}$ cells are associated with protective immunity against Plasmodium infection in mice. Eur $J$ Immunol. (2017) 47:685-91. doi: 10.1002/eji.201646699

Conflict of Interest Statement: The authors declare that the research was conducted in the absence of any commercial or financial relationships that could be construed as a potential conflict of interest.

Copyright (C) 2018 Faleiro, Karunarathne, Horne-Debets and Wykes. This is an openaccess article distributed under the terms of the Creative Commons Attribution License (CC BY). The use, distribution or reproduction in other forums is permitted, provided the original author(s) and the copyright owner(s) are credited and that the original publication in this journal is cited, in accordance with accepted academic practice. No use, distribution or reproduction is permitted which does not comply with these terms. 